The University of Akron

\title{
IdeaExchange@UAkron
}

July 2018

\section{Reflective Documentation as a Movement Potential: Two Digital Platforms Building a Professional Learning Community}

John Taylor

Amsterdam University of the Arts, jwetay@gmail.com

Defne Erdur

International Documentation of Contemporary Dance Education, defne.erdur@idocde.net

Please take a moment to share how this work helps you through this survey. Your feedback will be important as we plan further development of our repository.

Follow this and additional works at: https://ideaexchange.uakron.edu/docam

Part of the Adult and Continuing Education and Teaching Commons, Art Education Commons, Art Practice Commons, Dance Commons, Online and Distance Education Commons, and the Other Teacher Education and Professional Development Commons

\section{Recommended Citation}

Taylor, John and Erdur, Defne (2018) "Reflective Documentation as a Movement Potential: Two Digital Platforms Building a Professional Learning Community," Proceedings from the Document Academy: Vol. 5 : Iss. 1 , Article 11. DOI: https://doi.org/10.35492/docam/5/1/11

Available at: https://ideaexchange.uakron.edu/docam/vol5/iss1/11

This Conference Proceeding is brought to you for free and open access by University of Akron Press Managed at IdeaExchange@UAkron, the institutional repository of The University of Akron in Akron, Ohio, USA. It has been accepted for inclusion in Proceedings from the Document Academy by an authorized administrator of

IdeaExchange@UAkron.For more information, please contact mjon@uakron.edu, uapress@uakron.edu. 
Transmission of knowledge in dance teaching rests in oral tradition: passed on from body to body; inscribing, integrating, expanding knowledge in a variety of ways. This is the beauty of what we do. It also poses limitations on how we process our daily experience in teaching and learning dance, and in how we share what we know. ... Knee-deep in documentation practices through IDOCDE, we witness the transformative effects of noting, scribbling, drawing, pondering, and visualizing work of teaching. We have come to realize the significance of various reflective modes in developing and transforming the dance class-benefitting both the learning and the teaching. ... Our aim is to inspire dance teachers towards integrating documentation ideas into their practices - to guide and to give resources for the art of reflective teaching. MIND THE DANCE is a collection of essays, manuals, scores, exercises, and maps framing the politics around our practices, giving voice to a multitude of stances, ideas, and applications. Our objective is to motivate and empower the reader-teacher-artist towards finding their own ways into creative documenting, which in return may reframe and reshape the teaching and the practice of dance. (Erdur \& Kussmaul, 2017)

\section{Introduction}

This descriptive article aims to familiarize the reader with IDOCDE.net ${ }^{1}$ and MINDTHEDANCE.com. These digital platforms are designed to aid in establishing a professional learning community for contemporary dance teachers worldwide, as well as providing a platform for developing individual and creative documentation practices. The creation and maintenance of these two platforms is a collective, community-driven effort to generate a living archive. Since opening its doors in 2013, IDOCDE.net has proven its value as a source of inspiration and collaboration among dancers, choreographers and dance teachers. MINDTHEDANCE.com acts as a stepping-stone on the way to developing personal, sustainable, reflective and artistic documentation practices. The fruits of these practices are shared as IDOCs (the name used for documents) on IDOCDE.net.

There is a need to create forms of documentation that are drawn from and reflect the personal artistic processes from which they emerge. This necessity arises not only from the artistic and individual nature of dance practice, but also from its physical nature. Knowledge in dance lies not in words, but primarily, in the body and the senses. Dance research requires a process of sense making. Stanage (1987) tells us that reflection is instrumental in making us aware of the intuitive knowledge situated in the emotions and the body, and sense making occurs when cognitive (discursive) knowledge and the knowledge in the body are related through experience and reflection. What emerges from

1 International Documentation of Contemporary Dance Education 
this process of sense making is a personal embodied understanding (Taylor, 2016) of abstract concepts as they are experienced in the body and through the emotions. In order to address and share this personal embodied understanding creative forms of documentation are necessary.

In fact, documentation is an integral part of dance and movement teaching practices. In its most direct form a performance is a documentation of the knowledge emerging from a creative process. A dance class is a documentation of the research a teacher engages in with regard to learning and sharing the practice of dancing. Yet both are ephemeral in nature and usually (especially the teaching) end up not being recorded or documented as a body of knowledge. In the spirit of collaboration, co-creativity and individuality, which is at the heart of contemporary dance, IDOCDE.net and MIND THE DANCE encourage documentation - as a reflection of the artistic and teaching practices of those who create the documentation. Through these two websites documentation also becomes a collective process in which the dance work field, as a professional learning community, supports individual artists in their research. On the other hand, through collaboration and the sharing of that research, the professional learning community also guides the development the work field.

\section{The Dance Work Field as a Professional Learning Community}

A professional learning community is a concept borrowed from educational theory and arising from the idea of the "reflective practitioner" (Schön, 1983). Professional learning communities are groups of people sharing their reflections, practice, learning and development in a personal yet collective, collaborative and co-creative process contributing to the development of educational practice for the benefit of learners (Stoll, Bolam, McMahon, Wallace, \& Thomas, 2006). This coincides with the nature of artistic practice itself. As described in the theory of a/r/tography, the artist's practice requires her to take on the three roles of artist, researcher and teacher/learner in either a co-creative process of development or in the genesis of new knowledge (Sullivan, 2006). The exercise of these roles encompasses the same characteristics found in a professional learning community.

Standing at the heart of the dance community, as a personal learning community, is the support for each other in the development of practice as both artists and teachers. This has the potential to benefit the development of both the field and the next generation of dance artists and teachers. It is the aim of these two digital publications to form a bridge between reflective documentation and active (teaching) practices in the dance work field. At the same time, these digital publications support the development of individual and personalized, creative forms of documentation that reflect both the individual and personalized nature of the artistic process. A very good example for such a development of reflective practice feeding into the actual teaching practice is Anouk Llaurens' work-now titled 'Drawing as a Tool for Poetic and 
Polyphonic Dance Documentation." MIND THE DANCE hosts a revisiting of this work, developed since 2012 on the IDOCDE.net platform. ${ }^{2}$ Such an unfolding happens in a collaborative and co-creative environment in which the community supports the individual artists and pushes the work field forward in its development.

\section{IDOCDE.net}

IDOCDE.net is a community-run website that acts as a database front-end enabling the publishing and sharing of documentation concerning dance and dance teaching. It acts to facilitate the creation and continuity of a professional learning community within the dance and the dance education work fields. The website emerged from a project entitled "European Documentation of Contemporary Dance Education" and was funded through the Lifelong Learning Program of the European Union.

One of the foundation principles guiding the preparation and design of the website was to enable and encourage the creation of personal forms of documentation. It was necessary to create achievable standards for being an active member of the community, and the idea of personal forms of documentation would make participation in the website's community more attractive to dance artists and teachers for whom individuality is a strong characteristic. A commenting function and the possibility for co-authorship has been embedded from the very onset and have been utilized by the founding members of the website as examples to encourage collaboration. Later, the idea of collaboration was even taken further offline, through a two-year vocational project of the IDOCDE Project Team, called LEAP - designed so that contemporary dance teachers in Europe could meet offline, exchange and reflect on relevant practices in teaching methodologies.

Today, the website provides a simple interface (shown in Figure 1a) for entering direct text and adding pdf, image, video and sound files. It also provides the opportunity to create downloads for documents created outside of the interface. In this way, a member of the site can quickly and simply create a document and add it with keywords to the database. This is a one-step process. There is no curation or editorial review before a document is placed on the website unless the author asks for it from the editorial team or their colleagues who are active members of the IDOCDE.net. There are many documents on site, ranging from $\mathrm{PhD}$ dissertations and MA theses to poetry, drawings, sets of questions, interviews, templates...

2 See "Moving Drawing Writing: Re-visiting 'Drawing as a Tool for Poetic and Polyphonic Dance Documentation." See also: "Drawing as a Tool for Poetic and Polyphonic Dance Documentation," created out of the Reflex Outreach session that has taken place during the 4th IDOCDE Symposium, at ImPulzTanz-Vienna, International Dance Festival, in July 2016; Candoco summer lab 2014_-day 4; Spectrum of the senses II, a Tuning Scores and BMCbased workshop with Anouk Llaurens and Eva Maes; and the short report about the two side of touch + drawing feedback environment. 


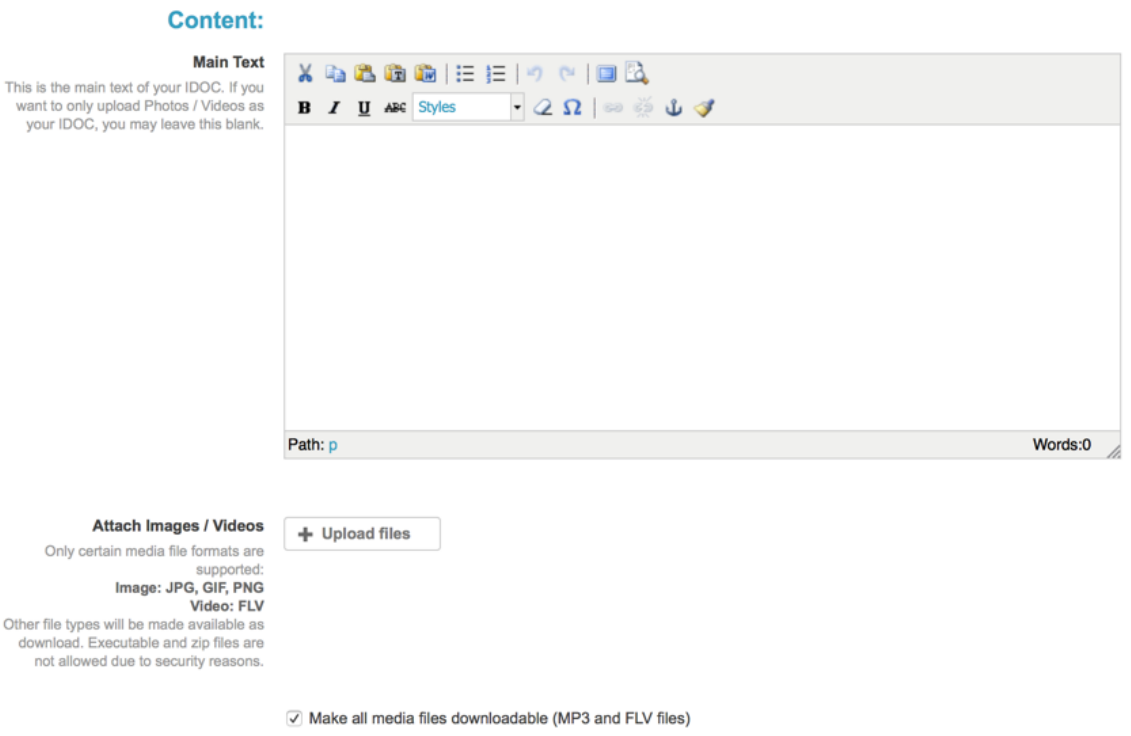

Figure 1 a. The simple interface provides both the opportunity for creating a document on IDOCDE.net, and for uploading an existing document.
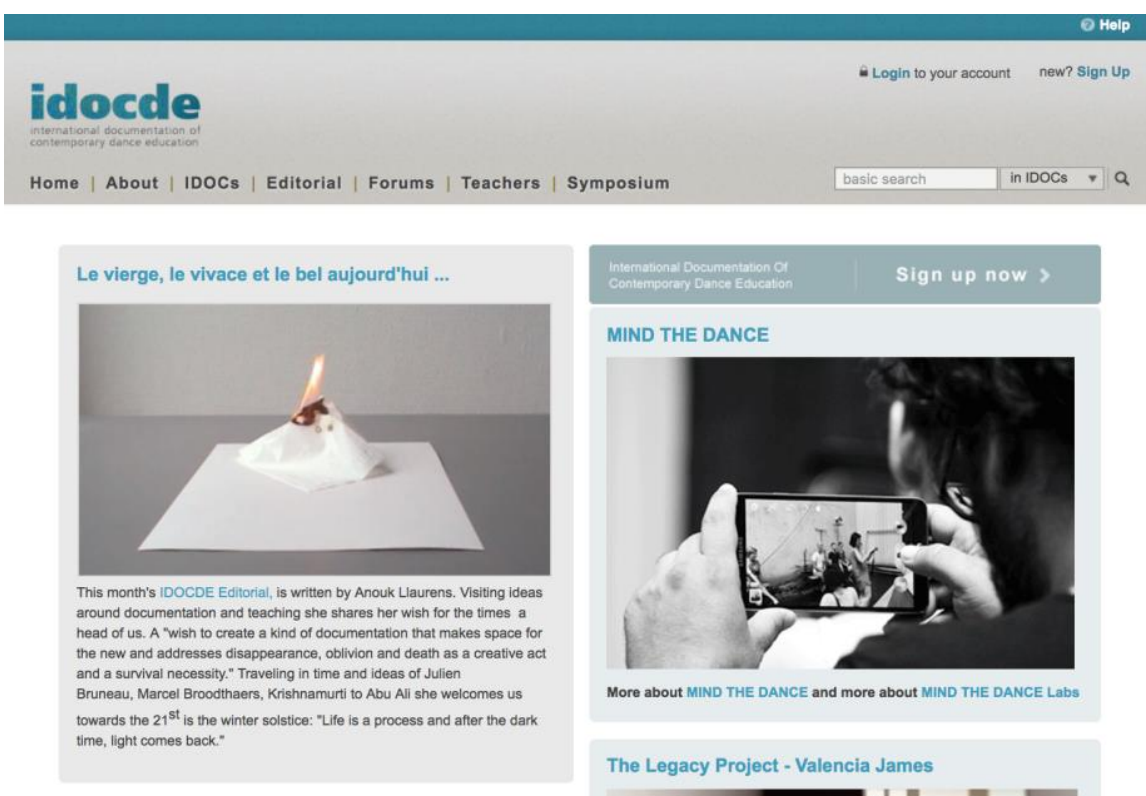

Food For The Day
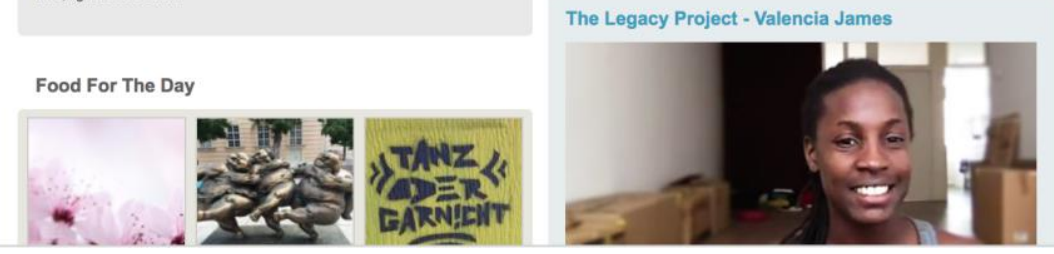

Figure $1 b$. The current uploaded documents are visible on the home page, as are the editorial and news boards. 
Since IDOCDE.net opened its digital doors in 2013, the community has grown to about 1400 members. As a platform for exchange and peer research IDOCDE.net has contributed to the development and increased visibility of contemporary dance teaching. IDOCDE.net also curates a yearly Symposium. The symposia take place during ImPulsTanz: Vienna International Dance Festival and bring together the dance teachers, dance practitioners, and theoreticians in fields related to dance. This is a physical meeting place in which the community can engage in the more corporeal actions at the heart of dance and dance teaching. The symposia aim at encouraging not only the analytical study of the different ways in which we think and speak about the practice of dancing, choreography, dance pedagogy, art and their participatory natures, but also the practical learning of how to do all those practices differently. This is through attentive moderation of formal and informal environments; scores that enable sharing, analyzing, questioning, reflecting, and documenting of prepared content and presentations created on the spot-disseminated through practice and theory. The collaborative, participatory, and practice-based research and sharing during the symposia is a continuation of the digital activities of the community. The activity and research during the symposia are fed back to the online community via new documentation on the website following the offline meetings. This establishes a generative interaction between the digital community and the physical community.

In response to the growth of IDOCDE.net, and in an effort to showcase the variety and personal nature of documentation, the IDOCDE Project Team invited a group of dance artists and documenters to co-create MIND THE DANCE.

\section{MIND THE DANCE: A Guide/Movement to Documenting Contemporary Dance/Movement Teaching}

MIND THE DANCE is a digital publication designed to inspire dancers and dance teachers to reflect on their own practice by means of creative documentation. The publication came into being as a result of the personal exploration of the REFLEX Europe Research Group. ${ }^{3}$ It is a guide for individual and communal reflection aimed at supporting the development of personal teaching practices and the sharing of those practices with others.

The digital publication itself is a platform for sharing that exploration and inspiring others to engage in their own personal research into documentation as a method of reflection upon their own artistic or teaching practice. Readers can work online or download the MIND THE DANCE articles for use in their own practice. The articles are available as individual pdf's, but the reader may also design their own personal set of articles, print them out, and put them into a MIND THE DANCE binder in book form. The templates and

3 REFLEX Europe is a three-year project funded by the Erasmus+ program of the European Union. 
inspirations found in these articles encourage the establishment of a personal practice of documentation, and guide the development of skills needed to tailor documentation practices to the needs of the individual and her practice. The new documents created by the readers of MIND THE DANCE can then be shared on the IDOCDE.net website to further inspire and guide the development of the community.

As a collection of essays, interviews, manuals, scores, exercises, and maps MIND THE DANCE helps the reader to frame the politics surrounding her contemporary dance teaching practices, giving voice to a multitude of stances, ideas, and applications for dance and dance teaching. As such, the content of MIND THE DANCE can also be utilized for the creative processes of performing artists, or for teaching in other fields of art.

MIND THE DANCE is organized into six chapters each of which addresses a different aspect of documentation. The six chapters are (1) Towards Documentation, (2) Weaving the Formal and Informal, (3) Coaching, (4) On Artistic Practice, (5) Writing, Moving and the Body, and (6) Further Reading. The articles of the Research Group have been arranged in such a way that they facilitate a logical progression in thinking about documentation practices. However, readers are also free to follow an independent trajectory following their own logic. This is accomplished through links within the texts to footnotes, glossaries, other articles, IDOCDE.net, and outside sources for further reading. This interactivity encourages the reader to go beyond the scope of the articles and search for deeper layers of interest.

The first chapter, "Towards Documentation," introduces the reader to questions and activities that will help her to frame, contextualize, and make concrete her personal processes of documentation. What is documentation? What is the purpose of documentation? Why does she want to engage in documentation? For whom is she creating the documentation? How does she reflect about and frame her activities? These questions influence the nature of the documentation the reader will be creating. Will she document the student's actions or her own? Is it important that the document will be understood by someone else, or is it just for her own reflection?

In the second chapter, "Weaving the Formal and Informal," the articles address more directly the context in which the reader will be creating her document. Context determines the nature of the document to be made. In the dance work field, there are generally two broad contexts in which a teacher engages with students: in an educational institution, and as a freelance teacher. These two contexts demand different approaches in the method of documenting. In an institutional setting a teacher must ask herself whether she creates this document for herself or if it is a request from the institution. Can she choose the form of the document or is there a required format that must be used? As a freelance teacher, she must consider whether the documentation is for her personal development, whether it is necessary for marketing or subsidy, or whether she wishes to contribute to the shared knowledge of the dance community. Within an institution there may be sophisticated equipment and 
technical assistance at hand, whereas a freelancer must often rely on the simpler less sophisticated technical options available to her. The context in which the reader finds herself influences the way in which she enters MIND THE DANCE and how she engages with her research into documentation.

"Coaching" and tools for documentation are the focus of the third chapter. In this chapter, the reader is introduced to various formats for documentation and their uses. She is also offered clear guidance to improve her technical skills with tools used to create documentation. She is given examples and information that empower her in developing personalized tools tailored to her specific needs. This chapter discusses mapping, provides templates, teaches technical skills in video and provides insight into how the reader can develop a sustainable practice in documentation.

The fourth chapter focuses "On Artistic Practice." What is the reader's artistic practice and how does that practice relate to her teaching and documentation. The articles in this chapter look at various artistic practices, and how they interact to provide new perspectives on personal practice. The value of artistic collaboration in documentation is also explored. As an example, a visual artist offers her specific skills in creating a visual representation of a teaching practice, and also provides another artist's perspective on the practice. The documenter sees her own practice with new eyes. This chapter encourages the reader to reflect upon her own artistic practice in relation to teaching, to engage with other forms of artistic practice in her documentation, and to engage in collaboration with other artists in order to avail herself of their expertise and perspective.

"Writing, Moving and the Body" is the title of chapter five. These are examples of documentation drawing from different techniques, methods, or art forms. A reader interested in exploring new techniques will find something to inspire her here. Video, audio, drawing, interviews, text, and metaphors drawn from artistic practice could all be central to the reader's documentation. These articles help the reader to discover what fits her needs.

This is followed by a chapter providing links to further reading. This section provides a pathway to information found on the IDOCDE.net website. This introduction allows the reader to engage with the history of these two websites. Via these links, she will enter some of the many discussions about dance and developments in personal practices that the sharing of documentation on IDOCDE.net has informed through recent years. This chapter is an incentive to participate in the professional learning community that IDOCDE.net has helped to create.

\section{Creativity from Practice}

An example of how documentation draws its form from practice is found in Kerstin Kussmaul's contribution to MIND THE DANCE entitled "Fascia as Metaphor and Narrator: Looking at the Things in Between." The practice, which 
is documented here, is briefly described in the following excerpt from the article.

I touch bodies, watch movement, and weave this into a dance and teaching practice. My physical experience is that images and feelings that arise when moving or being touched, often, originate in the fascial network. Fascia researcher Robert Schleip calls fascia our most sensitive and most important sensory organ (Schleip, 2015, p. 37). So what is the kind of information that fascia modality can provide us with? I propose that fascia as a sensory organ gives us a different kind of information than our somatic nervous system is able to give usotherwise it would not be worth the effort for our body to maintain this 'other' recording device. (Kussmaul, 2017)

Fascia in the body is the web of tissue that surrounds, connects, protects, and interpenetrates the muscles, bones, and organs in the body. It can be found throughout the body and as such implies an interconnection of the body as a whole. Following the concept of tensegrity introduced by Buckminster Fuller the fascia and muscles can be seen as an ocean of tension in which islands of compression (the bones) float (Kussmaul, 2017). This implies that the body acts as a decentralized system making it more capable of transmitting force without breaking.

When determining the content of a document the reader can use the central concepts of the practice as a metaphor to examine the practice. Taking fascia as central concept it makes sense to look at the connections between the elements of the practice rather than the separate elements themselves. The relationship between the teacher and student in a class becomes more interesting to examine than the separate actions of either one. Using fascia as a metaphor gives the researcher a specific point of view from which to examine the practice: A point of view that is connected to the practice itself.

The form of the document can also be influenced by this metaphor. Fascia connects and communicates throughout the body without the intervention of the brain. As such it represents the intuitive embodied knowledge of the body. Kussmaul suggests that rather than thinking about the practice with the brain the reader might let the body speak about the practice through a process of automatic writing or drawing. The following five steps suggest a method for doing just that:

1. Access your fascia by touch and movement right before your class. Use one or more of the introductory exercises or pick a fascia-minded music. Then think and read about one or more aspects of fascia, such as liquid crystals or tensegrity, and dance with it as long as you like.

2. Teach your class as usual. No fascia related theme is necessary for your class! Your fascia will be involved no matter what you do.

3. After your class, without much talking or socializing find a moment of rest. Then access your fascia as in 1, as you did before the class. Rest again if needed. 
4. Fascia rising from below the surface is the time to find fascia's voice. I suggest using free (automatic) writing or drawing. If you have an existing compatible practice, use it. If not, in the glossary you will find further links on how to free write. The point is to find a non-judgmental stream of consciousness in uninhibited and continuous writing or drawing. It does not need to make sense. A funny little discovery was that my fascia likes to speak as "we," not "I." Be also aware: do you let fascia speak or do you talk about fascia?

5. Sit back and look at what you wrote or drew, and gather your conclusions. You could also go on with a path from here.

This is just one example of how a central concept from the practice can help to inform and give shape to both the content and form in documentation. The documentation is then a part of the practice and offers a specific perspective with which to view and understand the practice.

\section{Two Websites at the Heart of the Professional Learning Community}

MIND THE DANCE provides insight, inspiration and support in developing a personal and sustainable documentation practice. It also provides clarity for each reader in discovering their personal reasons for documenting their practice. Most importantly, MIND THE DANCE links the reader to IDOCDE.net where they become a part of a growing professional learning community through sharing the fruits of their developing documentation practice with others and becoming a support in the growth and development of the dance work field.

The value of the two websites is the bridge they create between the individual's reflective documentation and the diversity of active (teaching) practices in the dance work field. By means of this connection the development of both the individual and the work field are supported. In this process, a living archive is created that acts as an evolving documentation of contemporary dance and dance teaching. The form of that documentation is drawn from the nature of the practice and the questions being asked. This of course creates some difficulties with regards to standardization, classification and the creation of relationships, which can simplify the process of finding information in a large database. In exchange, however, the database takes its form and structure from the work field from which it emerges and more clearly reflects that community. It would be interesting to see what kind of documents and database archives would emerge in response to the needs of the professional learning communities in other work fields. Through a community-driven process, what would emerge as a living archive for other art forms where knowledge in not primarily textual in nature? What new forms can be found for living archives? In the meantime, encouraged by MIND THE DANCE and IDOCDE.net, a professional learning community in contemporary dance and contemporary dance education has already begun the process of creating reflective documentation as a movement potential, one for the development of both the individual and the work field. 


\section{References}

Erdur, D., \& Kussmaul, K. (2017). MIND THE DANCE. Retrieved from http://mindthedance.com/ - foreword

Kussmaul, K. (2017). Fascia as metaphor: Looking at things in between. MIND THE DANCE. Retrieved from http://mindthedance.com/ article/131/fascia-as-metaphor-and-narrator

Schleip, R. (2015). Fascia as sensory organ. In R. Schleip \& A. Baker (Eds.), Fascia in Sport and Movement. Edinburgh: Handspring Publishing.

Schön, D. A. (1983). The reflective practitioner: How professionals think in action. New York: Basic Books.

Stanage, S. M. (1987). Adult education and phenomenological research: New directions for theory, practice, and research. Malabar, FL: Krieger.

Stoll, L., Bolam, R., McMahon, A., Wallace, M., \& Thomas, S. (2006). Professional learning communities: A review of the literature. Journal of Educational Change, 7(4), 221-258.

Sullivan, G. (2006). Research acts in art practice. Studies in Art Education, 1935.

Taylor, J. (2016). The benefits of the art practice based technique class for dance in higher education (Master teaching and learning in higher education). Amsterdam, Netherlands: Vrij Universiteit. 


\section{Appendix}

IDOCDE Partners (Original project title: European Documentation of Contemporary Dance Education):

- Kerstin Kussmaul / Wiener Tanzwochen (Vienna, A)

- Eszter Gál / Workshop Foundation (Budapest, HU)

- Jan Burkhardt / K3 - Zentrum für Choreographie | Tanzplan Hamburg (Hamburg, D)

- Stephanie Maher / Ponderosa Tanzland / (Stolzenhagen, D)

- Iñaki Azpillaga / Ultima Vez vzw (Brussels, B)

- Defne Erdur / Mimar Sinan Güzel Sanatlar Üniversitesi (Istanbul, TR)

- Charlotte Darbyshire (Former UK mentor: Gill Clarke) / Independent Dance (London, UK)

- Rasmus Ölme / Cullberg Ballet (Stockholm, S)

- Sophie Gérard / Le Pacifique / CDC (Grenoble, F)

- Malcolm Manning / Eastern Finland Sports Institute (Joensuu, FIN)

- Maja Delak / Emanat (Ljubljana, SLO)

- John Taylor / ICKamsterdam (Amsterdam, NL)

REFLEX Europe Partners (for the creation of MIND THE DANCE):

- Wiener Tanzwochen, Austria (coordinating partner)-RG: Sabina Holzer, Kerstin Kussmaul,

- Le Pacifique |CDC Grenoble, France, RG: Bertha Bermudez,

- ICKAmsterdam, Netherlands, RG: Barbara Meneses, Anouk Llaurens, Suzan Tunca, Amir Avraham, John Taylor

- SíN Arts Centre Budapest, Hungary-RG: Eszter Gal

- ElimSende Istanbul, Turkey-RG: Defne Erdur,

- K3 - Zentrum für Choreographie | Tanzplan Hamburg, Germany-RG: Andrea Keiz, Friederike Lampert,

- North Karelia College Outokumpu, Finland-RG: Ulla Mäkinen,

- Tanzplattform Rhein-Main, Frankfurt, Germany_-RG: Martin Streit 